\title{
Micromirror Arrays for Adaptive Optics
}

\author{
E.J. Carr
}

August 7, 2000

U.S. Department of Energy

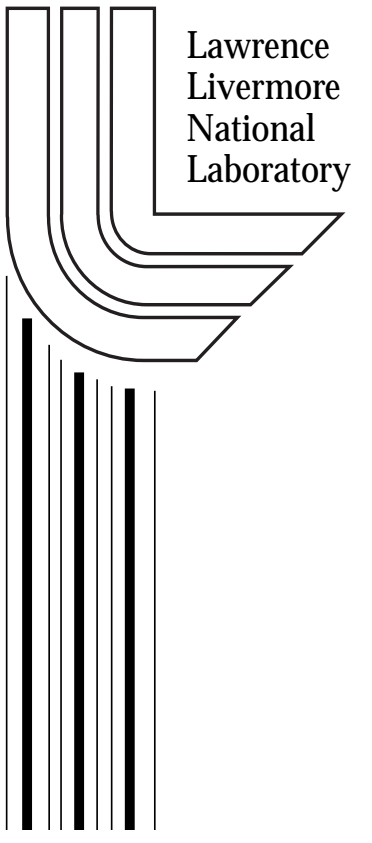




\section{DISCLAIMER}

This document was prepared as an account of work sponsored by an agency of the United States Government. Neither the United States Government nor the University of California nor any of their employees, makes any warranty, express or implied, or assumes any legal liability or responsibility for the accuracy, completeness, or usefulness of any information, apparatus, product, or process disclosed, or represents that its use would not infringe privately owned rights. Reference herein to any specific commercial product, process, or service by trade name, trademark, manufacturer, or otherwise, does not necessarily constitute or imply its endorsement, recommendation, or favoring by the United States Government or the University of California. The views and opinions of authors expressed herein do not necessarily state or reflect those of the United States Government or the University of California, and shall not be used for advertising or product endorsement purposes.

This work was performed under the auspices of the U. S. Department of Energy by the University of California, Lawrence Livermore National Laboratory under Contract No. W-7405-Eng-48.

This report has been reproduced directly from the best available copy.

Available to DOE and DOE contractors from the

Office of Scientific and Technical Information

P.O. Box 62, Oak Ridge, TN 37831

Prices available from (423) 576-8401

http://apollo.osti.gov/bridge/

Available to the public from the National Technical Information Service

U.S. Department of Commerce 5285 Port Royal Rd., Springfield, VA 22161

http://www.ntis.gov/

OR

Lawrence Livermore National Laboratory Technical Information Department's Digital Library http://www.llnl.gov/tid/Library.html 


\section{RESEARCH REPORT \\ Berkeley Sensor \& Actuator Center \\ September 2000}

Project Title: Micromirror Arrays for Adaptive Optics

Staffing and Level: $1 \mathrm{PhD}$ Student

Researcher: Emily J. Carr

Project Status: IN PROGRESS

Work Began: 6/15/1999

Advisor: Olav Solgaard

- Long-Range Goals

The long-range goal of this project is to develop the optical and mechanical design of a micromirror array for adaptive optics that will meet the following criteria: flat mirror surface $(\lambda / 20)$, high fill factor $(>95 \%)$, large stroke $(5-10 \mu \mathrm{m})$, and pixel size $\sim 200 \mu \mathrm{m}$. This will be accomplished by optimizing the mirror surface and actuators independently and then combining them using bonding technologies that are currently being developed.

\section{- Background}

Adaptive optics is a means to correct for wavefront distortions and aberrations on an optical field propagating through a turbulent medium. An adaptive optics system is comprised of many parts, including lenses, a deformable mirror, a wavefront sensor, a CCD camera, and a control system. The deformable mirror that performs the wavefront correction is the focus of my research. We are currently investigating a segmented deformable mirror that uses single crystalline silicon as the micromirror substrate. Micromachined mirrors can be fabricated in large arrays and can be integrated directly with actuators and electronic control circuitry. This will allow us to have an adaptive optics system that has an optimized mirror surface and actuator stroke.

\section{- Research Results, accomplishments and barriers}

A mask with test structures to characterize stress and stress gradients in SOI device silicon has been designed and fabricated. The objective is to test whether free-standing SOI films will produce sufficiently flat $(\lambda / 20)$ mirror surfaces for adaptive optics applications. Preliminary results of unreleased mirror structures are given in Figure 1. The $300 \mu \mathrm{m}$ mirror has a peak-to-valley measurement of $3.8 \mathrm{~nm}$. We do expect this to change once the mirror has been released. In addition to working on the SOI mirror substrates, characterization of a 140 actuator deformable mirror designed by Boston University is being done (see Figure 2) in collaboration with Lawrence Livermore National Laboratory. Deflections of $2 \mu \mathrm{m}$ have been reported when $240 \mathrm{~V}$ is applied to the electrostatic actuators. This deformable mirror was designed using a modified Cronos/JDS Uniphase process.

\section{- Problems to be addressed}

Characterization of the released SOI mirror structures and determining the stresses involved. Developing a high stroke $(5-10 \mu \mathrm{m})$ actuator that can be bonded to the SOI mirrors being developed. Continue doing the characterization of Boston University's deformable mirror and understand the actuation dynamics that are occurring in the mirror surface.

\section{- Research plan and one-year goals}

One year goals:

- Testing of SOI micromirrors to determine the optical quality.

- Developing bonding technologies and bonding the SOI micromirrors to dummy wafers.

- Design of compliant microactuators with optimized range of motion, voltage requirements, positioning accuracy and reliability.

\section{- Special resources required}

This research is being done in collaboration with Lawrence Livermore National Laboratory. 

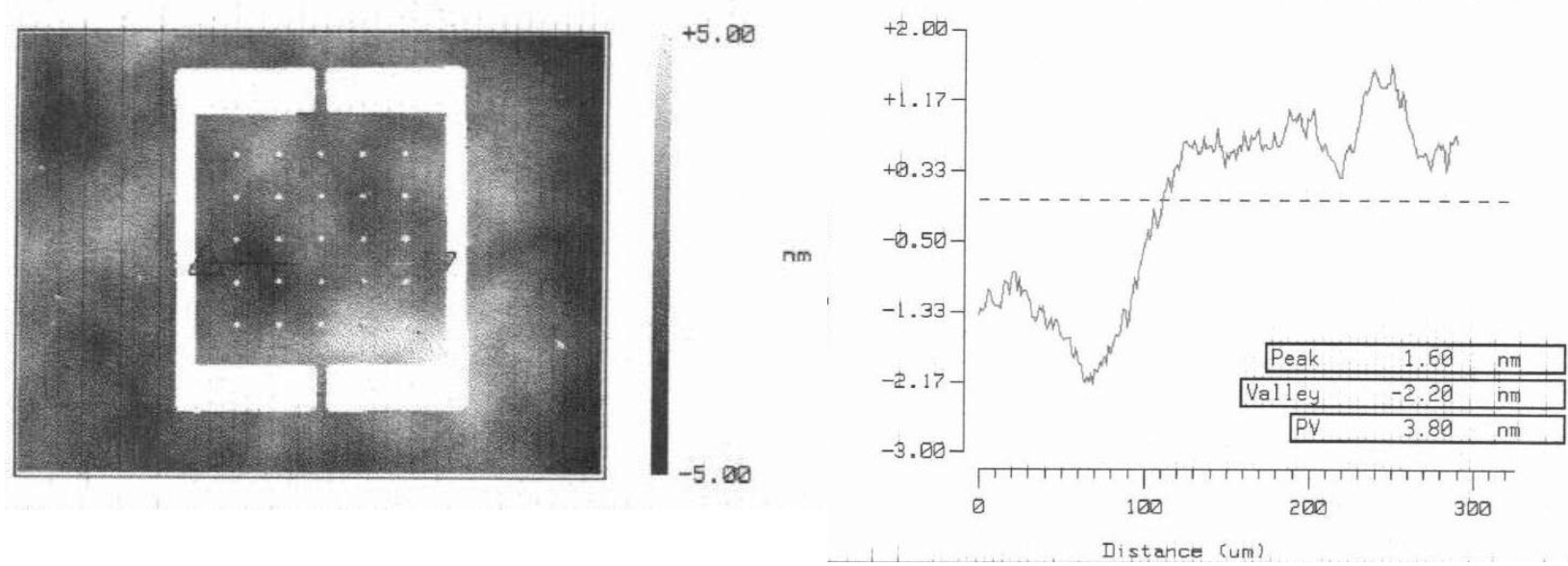

Figure 1. Zygo white-light interferometer microscope plot of a $300 \mu \mathrm{m}$ SOI unreleased mirror. A cross-sectional slice of the mirror has been made to obtain a surface profile of the mirror surface (shown on the right). A peak-tovalley measurement of $3.80 \mathrm{~nm}$ was obtained over the mirror surface.
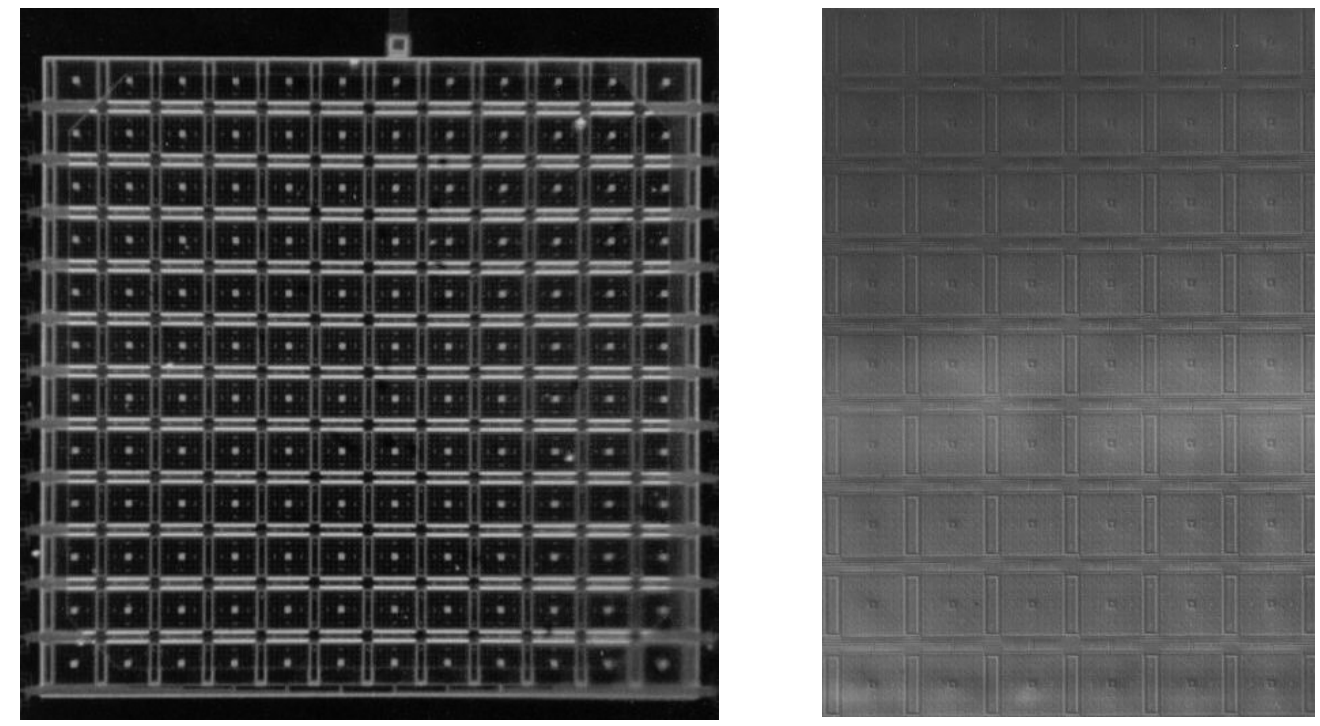

Figure 2. Boston University's 140 actuator continuous membrane deformable mirror. On the left is a image of the whole mirror surface. On the right is a magnified view of a portion of the mirror surface. With an operating voltage of $240 \mathrm{~V}, 2 \mu \mathrm{m}$ of deflection is achieved. 